\title{
CONSUMIDORES DA BASE DA PIRÂMIDE E AS RESTRIÇÕES AO LAZER
}

\author{
BASE OF THE PYRAMID CONSUMERS AND RESTRICTIONS ON LEISURE
}

DOI: http://dx.doi.org/10.12712/rpca.v6i2.130

\section{Ana Raquel Rocha}

Pontifícia Universidade Católica (IAG-PUC-Rio)

anaraquelcr@hotmail.com

\author{
Ângela da Rocha \\ Pontifícia Universidade Católica (IAG-PUC-Rio) \\ amc.darocha@gmail.com
}

\section{Resumo}

Este ensaio apresenta proposições sobre o comportamento de consumidores na base da pirâmide, grupo que tem se tornado importante para Marketing nos últimos anos em função do aumento de sua renda. Neste contexto, o investimento em atividades de lazer pode melhorar a qualidade de vida desses consumidores. Paralelamente, os estudos sobre restrições ao lazer buscam entender como tais restrições afetam as escolhas de lazer das pessoas. Neste trabalho articula-se sobre como os consumidores em questão lidam com suas restrições ao lazer e de que tipos de estratégias adaptativas se utilizam para diminuir os impactos das restrições que enfrentam.

Palavras-chave: Consumo. Consumidor na base da pirâmide. Restrições ao lazer. Lazer.

\begin{abstract}
This paper presents propositions about the behavior of consumers at the base of the pyramid, a group that has become important for marketing in recent years due to the increase of their income. In this context, investment in leisure activities can improve the quality of life of these consumers. In parallel, studies on constraints to leisure seek to understand how such restrictions affect leisure choices. This work examines how consumers at the base of the pyramid deal with restrictions on their leisure and what types of adaptive strategies are used to reduce the impacts of the restrictions they face.
\end{abstract}

Palavras-chave: Consumption. Consumer at the base of the pyramid. Constraints to leisure. Leisure. 


\section{Introdução}

Boa parte do que caracteriza o comportamento dos consumidores da base da pirâmide ainda é desconhecido pelos profissionais de Marketing. Há muito que ser descoberto sobre este segmento da população que, há pouco tempo, se tornou "visível" para o mercado (ROCHA, 2009), resultado do aumento da sua renda nos últimos anos (NERI, 2008; VEJA, 2011).

Percebe-se pouca familiaridade dos pesquisadores e profissionais de Marketing com este grupo de consumidores e isto se reflete não só nas muitas formas de referir-se ao grupo (baixa renda, base da pirâmide, emergentes, pobres etc.), mas também na disparidade dos intervalos de renda conferidos a ele, em estudos diversos. Neste estudo, utiliza-se a terminologia "base da pirâmide" para designar o grupo de consumidores de renda até 10 salários mínimos (NERI, 2008).

Ainda que apresentada tal delimitação, não se pretende discutir particularidades de um grupo tão grande de pessoas, no caso do Brasil, cerca de $52 \%$ da população (NERI, 2008). Castilhos e Rossi (2009), por exemplo, identificaram três gradações de status entre os moradores de um determinado morro: a primeira, a dos "pobres"; a segunda, dos "pobres-pobres" (aqueles para quem falta algum item percebido como de valor dentro da casa); e a terceira, a "elite do morro", composta pelos comerciantes locais. Cada uma das gradações de que tratam os autores possui características específicas, o que permite inferir que a condição financeira não afete a todas da mesma maneira e que o potencial de consumo, no âmbito do grupo, não seja o mesmo para todos os indivíduos que o compõem. 0 grupo das pessoas que estão na base da pirâmide, embora tenha na baixa renda o que os torna semelhantes em termos demográficos, não invalida que se identifiquem diferenças importantes, se investigado mais proximamente. Sua forma de consumo, no que tange a "ter as coisas" ou "não ter as coisas", pode transparecer algumas destas diferenças.

Observa-se que, tendo privilegiado as classes A e B em suas investigações (BARROS e ROCHA, 2009), os profissionais e pesquisadores de Marketing foram fundamentais na compreensão do que se sabe sobre os hábitos de consumo dos consumidores em geral. Todavia, conferiram certa generalização às suas descobertas e acabaram por contribuir para um descompasso entre o que pretendem aqueles que desejam aumentar a venda de seus produtos e os consumidores da base da pirâmide, de renda baixa, mas não inexistente, ávidos pelo consumo e sobre os quais se sabe pouco.

Assumindo que a limitação financeira caracteriza fortemente as pessoas na base da pirâmide, outros aspectos devem influenciar seu modo de consumo, de maneira a definir o que será consumido ou a dar pistas sobre sua predisposição, ou não, em ampliar suas aquisições. Afinal, se a renda deste grupo aumentou, levando ao aumento do consumo na base da pirâmide, como têm sido aplicadas "as sobras", ou aquilo que os economistas chamam de "renda discricionária" (parcela da renda que não está comprometida com gastos essenciais do indivíduo)? Pagando contas ou comprando novos produtos, assume-se nestetrabalho.

A "sobra" pode não ser exatamente uma quantia em dinheiro desvinculada de obrigações previstas no orçamento doméstico, mas revela uma predisposição em encontrar um mecanismo para lidar com a restrição financeira. Por exemplo, contrair empréstimos ou pagar prestações para antecipar o consumo. Nesta perspectiva, Brusky e Fortuna (2002) apresentam o conceito de "poupança invertida", referindo-se à obrigação que o consumidor cria para si de honrar compromissos assumidos em compras financiadas. A administração das "sobras" pode melhorar a qualidade de vida dos consumidores da base da pirâmide e servir de 
estímulo a repetições de consumo. Este argumento explica porque profissionais e pesquisadores de Marketing devem atribuir maior importância a estas "sobras" e a como são tratadas por este segmento.

Os produtos de lazer podem ser enquadrados como produtos hedônicos, ou seja, aqueles cuja experiência traz ao consumidor sensações, emoção e fantasia (HIRSCHMAN e HOLBROOK, 1982; KYLE e CHICK, 2002). No entanto, os consumidores da base da pirâmide enfrentam restrições para consumi-los, ainda que sejam exclusivamente financeiras. Alguns pesquisadores têm estudado o lazer na perspectiva daquilo que o restringe, para além da simples participação na atividade de lazer em si (JACKSON, 1993; SHOGAN, 2002). No contexto deste ensaio teórico, indaga-se: como os consumidores da base da pirâmide lidam com suas restrições de lazer?

Este ensaio tem como objetivo, portanto, associar a literatura existente sobre restrições ao lazer aos estudos disponíveis no Brasil sobre o consumo na base da pirâmide, de modo a gerar proposições a respeito de como esses consumidores lidam com restrições ao lazer, levando-se em conta as estratégias de que podem se utilizar para amenizá-las ou eliminá-las. Tais proposições podem contribuir para empresas e executivos de Marketing fornecendo pistas para o entendimento de como amenizar o impacto da restrição nos hábitos de consumo de lazer na base da pirâmide, e para estudiosos do tema, ampliando o conhecimento sob uma perspectiva ainda pouco explorada.

\section{Restrições ao lazer}

O estudo das restrições de lazer trata de aspectos que limitam ou impedem o lazer. Autores têm aprofundado as pesquisas relacionadas ao lazer, no sentido de entender o impacto das restrições sobre os indivíduos (GODBEY, CRAWFORD e SHEN, 2010, JACKSON, 2000; KYLE e MOWEN, 2004).

O modelo hierárquico de restrição de lazer de Crawford, Jackson e Golbey (1991) estabelece três níveis de restrição: intrapessoal, interpessoal e estrutural. 0 nível intrapessoal diz respeito às condições psicológicas e às características pessoais que interagem com as preferências de lazer: são avaliações subjetivas do quão adequada é a atividade para o indivíduo. 0 nível interpessoal dá conta das restrições decorrentes das relações entre as pessoas para a realização de uma atividade, ou a dependência de outras pessoas para que a atividade possa ocorrer (por exemplo, a necessidade de um par para iniciar aulas de dança de salão). 0 nível estrutural de restrição de lazer corresponde ao conjunto de fatores estruturais que impede o indivíduo de participar de uma atividade de sua preferência, tais como recursos financeiros, estrutura física disponível, estágio do ciclo de vida, dentre outros.

Jackson (1993) utilizou-se de uma análise de clusters para identificar a combinação de diferentes tipos de restrições de lazer. 0 autor chegou a seis clusters: (i) tempo (restrições decorrentes de compromissos de trabalho ou com a família); (ii) tempo, custo e acessibilidade (uma combinação de tempo disponível, custo de participação e acesso às instalações em que a atividade de lazer aconteça); (iii) custo de participação; (iv) custo, instalações e consciência (que combina o custo de participação com problemas associados às instalações envolvidas no lazer e ao conhecimento de oportunidades disponíveis); (v) acessibilidade e consciência (em que os fatores externos relacionados à disponibilidade de oportunidades para a prática do lazer e o conhecimento e acesso às instalações são o que restringem); e, por último, (vi) relativamente sem restrições. 
Os clusters identificados por Jackson incluem o conhecimento e a consciência da existência do lazer. A restrição configura-se pela falta destes itens e, sendo assim, é possível, por exemplo, que pessoas da base da pirâmide não saibam onde praticar esportes como golfe ou tênis, ainda que exista a oferta, em função da pouca familiaridade com esses esportes. A familiaridade está relacionada com o aspecto da divulgação e da acessibilidade ao lazer, mas também decorre do quão adequada é a atividade de lazer para o consumidor. As restrições representativas da falta de habilidade para determinado tipo de lazer não foram citadas por Jackson no referido trabalho. A prática do futebol pode exemplificar este tipo de restrição. Mesmo que se trate de um esporte difundido em todos os segmentos da sociedade, é possível que uma pessoa tenha o desejo de jogar futebol, mas não tenha habilidade em fazê-lo.

Hultsman (1995), baseado no trabalho de Jackson, estabeleceu quatro dimensões de restrições de lazer: acessibilidade, razões pessoais, custos e instalações. Apresentadas desta forma, as dimensões não destacam um aspecto importante quando se trata da base da pirâmide: a baixa escolaridade das pessoas deste grupo, como restritiva do entendimento do que envolve o lazer em si. 0 estudo de Castilho e Rossi (2009) sobre consumo, posição social e distinção entre famílias de determinada comunidade da base da pirâmide ressalta a baixa escolaridade dos pesquisados, sem fazer, no entanto, menção a de que modo o nível de escolaridade afetaria seu entendimento sobre as opções de consumo.

O fator consciência, apontado por Jackson (1993), diz respeito ao conhecimento que se tem acerca das opções de lazer disponível e à acessibilidade às instalações onde a atividade ocorre. Por exemplo, pode-se esperar que, para o consumo de viagens pela população da base da pirâmide, seja necessário algum grau de conhecimento (no que se refere aos meios de transportes, destinos e formas de pagamento disponíveis), compatível com determinado nível de escolaridade. Além disso, níveis de escolaridade diferentes devem corresponder a condições financeiras e potencial de consumo distintos, mesmo entre consumidores da base da pirâmide.

A partir dessas considerações, apresenta-se a seguinte proposição:

Proposição 1: Consumidores da base da pirâmide tendem a apresentar algumas dificuldades de compreensão de alternativas de lazer decorrentes de seu baixo nível deinstrução.

Algumas críticas feitas por Jackson (2000) em relação aos estudos sobre restrições de lazer dizem respeito à ênfase na participação versus não participação na atividade de lazer; à investigação apenas de restrições estruturais, negligenciando as restrições intra e interpessoais; e à ênfase em restrições como sendo obstáculos, desconsiderando as estratégias adotadas para se sobrepor a determinada restrição. No que se refere aos consumidores da base da pirâmide, outros tipos de restrições, além da financeira, não devem ser desprezados já que, isoladamente ou de forma combinada, podem influenciar suas escolhas de lazer. Por exemplo, boa parte deste segmento vive longe do trabalho e, desta forma, o período correspondente ao deslocamento da casa para o trabalho e do trabalho para a casa pode afetar negativamente sua disponibilidade de tempo para a prática do lazer. Estas observações conduzem à seguinte proposição:

Proposição 2: Consumidores da base da pirâmide podem apresentar como restrição ao lazer a baixa disponibilidade de tempo, em função de longos deslocamentos para o trabalho.

Também a questão de gênero deve ser considerada, assumindo que os indivíduos desempenham vários papéis no contexto social. Às mulheres é conferida dupla jornada de 
trabalho, o que impacta sua disponibilidade de tempo. Isso é evidenciado em uma revisão de literatura, realizada por Henderson (1996), ao examinar os muitos "tamanhos" do lazer na vida das pessoas. Um dos "megatemas" indicados pela autora, o gênero, considera que as diferenças dos padrões de lazer entre homens e mulheres são mais contextuais que biológicas e que, quanto mais papéis as mulheres assumem, maior a possibilidade de diminuírem seu lazer pessoal. No caso da base da pirâmide, a multiplicidade de papéis exercidos pelas mulheres seria ainda mais evidente, dado que não têm acesso, por exemplo, a serviços domésticos, ou a muitos produtos que facilitam o trabalho doméstico. Em decorrência, podese supor que:

Proposição 3: A dupla jornada de trabalho do segmento feminino da base da pirâmide impacta negativamente sua disponibilidade de tempo para o lazerpessoal.

Na tentativa de operacionalizar o modelo de restrições de lazer de Crawford, Jackson e Golbey (1991), Diniz e Motta (2006) trabalharam o tema com foco no lazer das pessoas da terceira idade. Chegaram a oito fatores, complementares ao modelo original: receio, apoio interno e externo (fatores como energia, saúde, incentivo de terceiros etc. afetando a participação no lazer), recursos financeiros, tempo (disponibilidade de tempo para o lazer), interação social, medo do transporte, companhia (alguém com quem se possa desfrutar do lazer) e busca de experiências. 0 "receio" refere-se à necessidade de consumidores da terceira idade de se sentirem seguros na realização de uma atividade de lazer. Este é um exemplo de restrição intrapessoal que indica a condição psicológica do indivíduo. No estudo, os autores não mencionam a que classes sociais pertencem os entrevistados, mas é possível imaginar que seus achados sejam ainda mais aplicáveis a pessoas da terceira idade no segmento da base da pirâmide. Esses consumidores sofreriam mais o impacto da falta de segurança física (por exemplo, por não disporem de seguro-saúde, no caso de acidentes, ou por não terem dinheiro para adquirir outras formas de lazer se uma determinada compra de lazer fracassar). Daí decorre a seguinte proposição:

Proposição 4: Consumidores de terceira idade na base da pirâmide podem restringir suas atividades de lazer mais do que os de outras classes sociais em função de preocupações relativas a sua segurança.

A pouca familiaridade com determinado lazer ou com aquilo que o envolve pode gerar o mesmo tipo de insegurança em consumidores da base da pirâmide. Por exemplo, há ofertas de passagens de avião cuja forma de pagamento aumenta as chances de consumidores da base da pirâmide viajarem por um meio de transporte, até bem pouco tempo, usufruído apenas pelos de status social mais elevado. A contradição está em facilitar o acesso ao meio de transporte, mas não os trâmites a ele atrelados, de forma que, não sabendo lidar com o processo de embarque, desde o check-in até a busca do gate correto, o consumidor inexperiente se deixe tomar pela insegurança (DINIZ e MOTTA, 2006).

Proposição 5: A pouca familiaridade do consumidor da base da pirâmide quanto às ofertas de produtos de lazer e a forma de usufruí-las pode se constituir em importante restrição ao lazer deste segmento.

O trabalho de Chick e Dong (2003) estimula uma reflexão sobre aspectos culturais como restritivos ao lazer. Eles testaram o modelo de restrições de Crawford, Jackson e Godbey (1991), que tinha como foco a sociedade norteamericana, nas culturas japonesa e chinesa. Embora tenham validado o modelo, chamam a atenção para as restrições culturais, no caso do 
referido estudo, ligadas à tradição, elemento fortemente presente em ambas as culturas orientais. Assim como a tradição, a religião também pode restringir o lazer dos consumidores da base da pirâmide. 0 estudo de Barros e Rocha (2009) revela a influência da religião no consumo de empregadas domésticas. Segundo o estudo, as empregadas evangélicas distinguiam-se das católicas pela busca de um consumo "racional", em que são evitados "excessos", "imediatismos" e "desperdícios".

Proposição 6: A orientação religiosa pode atuar como mecanismo de restrição a certas atividades de lazer entre consumidores da base da pirâmide.

A percepção e o conhecimento do consumidor acerca do que seja uma alternativa de lazer dizem muito sobre suas escolhas nesta categoria. "Há alternativas de consumo que, por desinformação ou simples exclusão do quadro cognitivo das pessoas, não chegam sequer a ser consideradas" (MATTOSO e ROCHA, 2009). Assim, se para as pessoas da base da pirâmide ficar em casa basta como opção de lazer, dificilmente as restrições associadas às atividades fora daquele ambiente serão percebidas ou as afetarão de alguma forma, de modo que podem nem se sentir restringidas àquele contexto.

Proposição 7: Certas restrições ao lazer podem não ser percebidas pelos consumidores da base da pirâmide e, portanto, não afetá-los, por desconhecimento de algumas atividades de lazer disponíveis.

Também o olhar de terceiros pode influir nas decisões de consumo deste grupo. Em função da limitação financeira, é imperativo à população da base da pirâmide o gasto com o essencial. Investir em viagem pode ser percebido por terceiros (vizinhos, parentes etc.) como "não saber gastar" ou "comer o dinheiro", uma vez que as viagens não figuram na listas das atividades de lazer mais usuais destas pessoas (CASTILHO e ROSSI, 2009). 0 julgamento em relação à atitude destes consumidores pode ser fator de restrição.

Proposição 8: O olhar de terceiros e o julgamento associado a ele podem atuar como fator restritivo ao lazer de consumidores da base da pirâmide.

O estudo de Diniz e Motta (2006), tomando em consideração o consumidor de mais idade, sugere que as restrições interpessoais, interpessoais e estruturais não sejam prerrogativa de um segmento específico da sociedade. 0 desenho de um modelo básico para operacionalização do modelo restrições de lazer de Crawford, Jackson e Godbey (1991) para pessoas na base da pirâmide, pode levar à identificação de particularidades deste segmento que restrinjam seu lazer, em função de questões diferentes das que ocorre para outros grupos de consumidores.

Proposição 9: Um modelo de restrições de lazer elaborado para consumidores da base da pirâmide pode trazer à tona questões, particulares para este grupo de pessoas, que diferencie seu consumo de lazer de outros grupos de consumidores.

\section{Estratégias adotadas pelos consumidores da base da pirâmide para lidar com restrições de lazer}

Algumas formas de lazer populares em grandes cidades impõem, direta ou indiretamente, que se tenha dinheiro para o consumo no local em que ocorrem. Por exemplo, na cidade do Rio de Janeiro, um passeio familiar à Quinta da Boa Vista, uma comemoração de aniversário na Feira 
de Tradições Nordestinas ou a ida ao baile funk em um sábado à noite são alternativas de lazer em que o fato de ter dinheiro para consumir no local confere diferencial à experiência que se tem. Não tê-lo, neste caso, configura uma restrição ao lazer do consumidor.

A restrição, no entanto, não deve ser tomada como negativa em sua totalidade. É o que propõem Kleiber et al. (2008) quando abordam a questão, destacando os benefícios promovidos pela restrição. Os autores ressaltam a limitação de escolha como contraponto ao excesso de escolha, em que o segundo acaba por dificultar a escolha em si. Também as regras de jogos, que aparecem como restritivas da atividade, estimulam os jogadores a desenvolverem habilidades para contorná-las. As restrições de espaço nas atividades de lazer são citadas pelos autores como algo que garante que a atividade seja bem executada, uma vez que atendem a especificações previamente estabelecidas. 0 intuito é destacar o benefício potencial de crescimento e desenvolvimento das pessoas diante das restrições de lazer a que são submetidas. As restrições ao lazer que enfrentam os consumidores da base da pirâmide podem servir de estímulo para a adoção de estratégias para revertê-las.

Estudos chamam a atenção para as estratégias adotadas pelas pessoas para diminuir o efeito das restrições ao lazer, nem que para isto seja necessário alterá-lo ou modificar qualquer aspecto de suas vidas (JACKSON, 2005; SON, KERSTETTER e MOWEN, 2008). Contrair empréstimo é uma estratégia adotada pelos consumidores da base da pirâmide para a resolução de problemas financeiros, tendo como fontes usuais as financeiras, os parentes ou os patrões (BRUSKY e FORTUNA, 2002; MATTOSO e ROCHA, 2009). O crédito informal, fruto das relações interpessoais, portanto, tem importância para este público. Pode-se considerar o ato de comprar fiado no bar, por exemplo, como estratégia para superar a restrição financeira a certo tipo de lazer.

Proposição 10: Os consumidores da base da pirâmide utilizam o crédito formal ou informal como estratégia para reverter as restrições ao lazer enfrentadas.

Veloso et al. (2009) estudaram a experiência de consumidores da base da pirâmide no supermercado, abrindo caminho para entender uma das estratégias adotadas por este grupo para lidar com as restrições ao lazer. Embora a pesquisa enfoque a atitude da criança no supermercado, também aponta para o consumo utilitário do adulto, voltado a suprir suas necessidades básicas. No entanto, no mesmo estudo, a ida ao supermercado com as crianças é traduzida como "lazer nos fins de semana". Assim, atribuir um caráter meramente pragmático e racional ao comportamento de consumo deste segmento é desprezar a sua capacidade de se utilizar de estratégias específicas para se sobrepor a restrições delazer.

Proposição 11: Os consumidores da base da pirâmide utilizam os momentos de compras como experiências de lazer e não como atividade exclusivamente utilitária.

O significado do lazer sugere ser diferente para cada pessoa. Outro dos "megatemas" identificados por Henderson (1996), o "contínuos de significados”, dá conta de que o lazer tem definições múltiplas e variadas, dependendo de se tratar de lazer pessoal ou social. A freqüência a cultos religiosos, por exemplo, pode significar obrigação, mas também pode representar lazer por propiciar socialização e, conseqüentemente, o estreitamento de relações interpessoais. Pode-se supor que, para consumidores da base da pirâmide, as atividades religiosas possam se constituir mais intensamente em forma de lazer, em função exatamente da oportunidade de socialização que oferecem (BOHN, 2004). 
Proposição 12: A socialização proporcionada pelos cultos religiosos é percebida como atividade de lazer entre consumidores da base da pirâmide.

Para aqueles cujo fato de ficar em casa substitui o lazer fora dela, a compra de eletrodomésticos, em especial, a televisão para ver a novela e os jogos de futebol e a geladeira, para a cerveja, é essencial. Ressalta-se aqui, a importância dos aparelhos eletrônicos televisão, geladeira, aparelhos de som, DVD, computador, dentre outros - instrumentos que ajudam a promover o lazer, não só para "colocar os pobres em contato com a modernidade e a sociedade de consumo", mas também para possibilitar a socialização (CASTILHOS e ROSSI, 2009; PONCHIO e ARANHA, 2009).

Proposição 13: Os consumidores da base da pirâmide adquirem bens de consumo voltados para o lazer "dentro de casa" como forma de superar restrições financeiras ao lazer.

Proposição 14: O lazer "dentro de casa" por consumidores da base da pirâmide pode ser tanto de natureza pessoal como social.

Somando-se a isto a ênfase conferida pelos consumidores da base da pirâmide em montar a casa com todos os apetrechos percebidos como de valor (CASTILHOS e ROSSI, 2009), pode-se supor que este consumo seja estratégico não só para que tenham lazer dentro da sua própria casa, como também em sua própria comunidade, ambiente que conhecem e onde são aceitos.

Proposição 15: Formas de lazer dos consumidores da base da pirâmide em suas próprias comunidades são utilizadas como estratégia para resguardá-los de restrições associadas a ambientes pouco familiares.

O celular aumenta a lista dos produtos consumidos por pessoas da base da pirâmide e, neste ensaio, são considerados mais do que uma ferramenta tecnológica. Por disponibilizarem jogos e aplicativos que permitem aos seus usuários acesso às redes sociais e promovem divertimento, o que é uma premissa do lazer. Uma estratégia adotada pelas pessoas da base da pirâmide, relacionada ao uso do celular, diz respeito à limitação de algumas delas na compreensão de como usar o aparelho. 0 estudo de Barbosa, Hor-Meyell e Motta (2009) sobre o uso do celular por consumidores da baixa renda, chama a atenção para o apelo de alguns deles, limitados tecnologicamente, pela ajuda de seus parentes (normalmente mais jovens e próximos), com o objetivo de diminuir o impacto dessa restrição. São os filhos, sobrinhos, afilhados etc., os responsáveis por esclarecê-los em suas dúvidas ou apresentá-los aos recursos de que dispõem em seus aparelhos celulares. Outra forma de lidar com a restrição indicada pelos informantes no estudo é não comprar modelos tecnologicamente complexos.

Proposição 16: Os consumidores da base da pirâmide utilizam sua rede familiar e de amigos como estratégia para superar restrições ao lazer provenientes da falta de conhecimento na utilização de produtos tecnológicos.

Proposição 17: Os consumidores da base da pirâmide podem adquirir modelos menos complexos, do ponto de vista tecnológico, como estratégia para superar suas restrições ao lazer provenientes da falta de conhecimento na utilização de produtostecnológicos.

Proposição 18: 0 uso de estratégias por consumidores da base da pirâmide para se sobrepor a restrições ao lazer provenientes da falta de conhecimento na utilização de produtos tecnológicos pode diminuir essas restrições, mas não garantir sua total eliminação.

Um dado importante na literatura de consumo na base da pirâmide diz respeito ao uso do nome, como fator de distinção. No contexto aqui apresentado, "ter nome", termo cunhado do 
estudo de Mattoso e Rocha (2009), amplia as chances de se aderir a uma atividade de lazer já que significa que a pessoa, em função de ter seu nome "limpo", pode ter acesso a crédito. "Ter nome" é um facilitador, mas não uma solução em sua totalidade no caso das pessoas da base da pirâmide. Há quem tenha o nome "limpo", mas não tenha renda suficiente para assumir parcelas mensais, ficando impedido de adquirir determinados produtos e serviços. De qualquer forma, "quando se tem 'nome' surge a 'pessoa' e todos os privilégios ligados a ela". Poder comprar e pagar parceladamente é um destes privilégios, facilitando o consumo de produtos e serviços que promovem lazer para as pessoas da base da pirâmide como, por exemplo, um computador (para baixar música, jogar, utilizar redes sociais etc.) ou um pacote de viagem.

Proposição 19: Os consumidores da base da pirâmide têm maior interesse que outros grupos em utilizarem-se de estratégias para manter "o nome limpo", de forma a que isto não venha a comprometer o consumo relacionado ao lazer.

O uso estratégico da socialização pode servir para suprir restrições de consumo, como no estudo de Barros (2009), que revela aspectos da sociabilidade e da construção de relacionamento a partir do uso de tecnologia no ambiente doméstico. Os resultados do estudo sugerem que a restrição por não se ter um computador, por exemplo, pode ser negociada por meio das relações interpessoais, quando aquele que tem o computador compartilha o seu uso com os que não têm.

Proposição 20: Os consumidores da base da pirâmide utilizam sua rede familiar e de amigos como estratégia para ter acesso a produtos ou serviços de lazer.

Tendo apresentado algumas restrições ao lazer que consumidores da base da pirâmide têm que enfrentar e algumas estratégias das quais estejam dispostos a fazer uso para lidar com tais restrições, este estudo não pretende esgotar estes temas. Algumas restrições e estratégias apresentadas não devem ser prerrogativas deste grupo específico de consumidores (restrições de tempo e a participação de outros para suprir limitações tecnológicas são exemplos). No entanto, pode-se supor que as restrições ao lazer afetem este grupo específico de consumidores mais intensamente, de modo a intimidá-los diante de determinados consumos, por vezes, nem cogitá-los e, consequentemente, diminuir seu esforço em lidar com as restrições, o que leva a pesquisadora à seguinte proposição de caráter geral:

Proposição 21: Restrições ao lazer afetam mais intensamente consumidores da base da pirâmide, de modo a comprometer seu consumo e diminuir seus esforços em adotar estratégias para lidar com tais restrições.

\section{Considerações finais}

0 interesse de pesquisadores e profissionais de Marketing pelos consumidores da base da pirâmide é recente. Há muito que ser pesquisado e difundido sobre os hábitos de consumo de um segmento da população, até pouco tempo, "invisível" para Marketing. O objetivo deste ensaio foi gerar proposições acerca das restrições ao lazer enfrentadas pelos consumidores na base da pirâmide e como esses consumidores lidam com essas restrições ao lazer, partindo de estudos sobre restrições ao lazer e sobre consumo na base da pirâmide.

Da literatura sobre restrição ao lazer destaca-se o modelo de Crawford, Jackson e Golbey (1991). Os consumidores da base da pirâmide estão submetidos à limitação financeira, uma 
restrição estrutural. Adotou-se a premissa de que, embora a restrição financeira comprometa as escolhas de lazer dos consumidores da base da pirâmide, não seria esta a única restrição ao lazer por eles enfrentada. Foram então construídas proposições sobre outras restrições enfrentadas no consumo de lazer na base da pirâmide.

A restrição de tempo, em função do longo deslocamento da casa para o trabalho e vice-versa, pode também comprometer os consumidores do segmento em questão em sua participação em atividades de lazer. Também os papéis sociais influenciam na disponibilidade para o lazer. Em especial, as mulheres da base da pirâmide, que trabalham dentro e fora de casa, têm seu tempo comprometido.

Restrições interpessoais e intrapessoais também são enfrentadas por consumidores da base da pirâmide. A pouca familiaridade com determinada atividade de lazer implica em não participação no lazer em si e, no caso dos consumidores da base da pirâmide, algumas atividades podem revelar-se restritas por sua natureza. Aquelas que demandarem maior investimento de dinheiro e tempo devem mostrar-se mais restritivas que outras. Também a adequação da atividade às habilidades de que dispõe o consumidor pode impulsioná-lo ou restringi-lo na participação em uma atividade de lazer. Chama-se a atenção para uma restrição intrapessoal que sugere ser particular dos consumidores da base da pirâmide: a baixa escolaridade. Esta restrição afeta o nível de compreensão de informações disponíveis que ajudam a ampliar a escolha do consumidor.

A investigação de como os consumidores da base da pirâmide lidam com as restrições de lazer considerou, ainda, dois outros aspectos: 1) a percepção da restrição em si, já que, se a pessoa não entende algum fator como restritivo, não se percebe como restringido diante dele; e 2) o olhar de terceiros restringindo o lazer escolhido, assumindo que pessoas comprometidas com gastos tidos como "essenciais", podem ser comprometidas com esta imagem e, por isso, evitem gastar com aquilo que os outros percebem como "jogar dinheiro fora".

Identificadas as restrições intrapessoais, interpessoais e estruturais, foram analisadas algumas estratégias utilizadas pelos consumidores para fazer face às restrições identificadas, gerando-se outro conjunto de proposições.

Montar a casa com tudo o que se precisa para "viver bem" é uma maneira de contornar a limitação financeira, no sentido de garantir dentro de casa o lazer pelo qual seria necessário fazer algum tipo de desembolso fora dela. Além disso, mantém o sujeito em sua comunidade, local com o qual está familiarizado e é aceito. 0 acesso ao crédito tem papel fundamental neste contexto, permitindo a aquisição de bens que contribuem para o lazer dentro de casa, além de facilitarem o processo de socialização e o relacionamento interpessoal.

Dentre os produtos que têm consumido, o celular e o computador são exemplos dos que contribuem para a socialização e lazer destes consumidores (jogos, redes sociais etc.). A literatura sugere que, em relação ao primeiro, a população da base da pirâmide adota uma estratégia para maximizar o seu uso: os usuários limitados tecnologicamente pedem ajuda para seus parentes - mais jovens - para esclarecer suas dúvidas e maximizar o uso do aparelho. Já a restrição decorrente de não possuir um computador pode ser negociada estrategicamente por meio das relações interpessoais de que se dispõe.

Entender como consumidores da base da pirâmide se utilizam de estratégias para mitigar ou eliminar restrições de lazer pode revelar uma lacuna que pode - e deve - ser preenchida por produtos e serviços adequados. Este ensaio apoia-se na literatura de restrição de lazer e 
consumo na base da pirâmide no Brasil, não tendo a intenção de esgotar o assunto. Espera-se que estas reflexões sirvam à geração de hipóteses que, ao serem testadas, contribuam para aprofundar o conhecimento sobre o comportamento de consumo na base da pirâmide.

Referências

BARBOSA, P. B.; HOR- MEYLL, L. F.; MOTTA, P. C. O Uso de Celular Pré-Pago por Consumidores de Baixa Renda. Consumo na Base da Pirâmide: Estudos Brasileiros, cap.6, Rio de Janeiro, Mauad, 2009.

BARROS, C.; ROCHA, E. Lógica de Consumo em um Grupo das Segmentos Populares: Uma Visão Antropológica de Significados Culturais. Consumo na Base da Pirâmide: Estudos Brasileiros, cap. 2, Rio de Janeiro, Mauad, 2009.

BARROS, C. "Na Internet Todo Mundo é Feliz": Sociabilidade e Familiaridade no Universo das Segmentos Populares. Consumo na Base da Pirâmide: Estudos Brasileiros, cap.5, Rio de Janeiro, Mauad, 2009.

BOHN, S. R. Evangélicos no Brasil. Perfil socioeconômico, afinidades ideológicas e determinantes do comportamento eleitoral. OPINIÃO PÚBLICA, Campinas, Vol. X, no 2, Outubro, 2004, p. 288-33.

BREternitZ, V. J. Contribuições ao Processo de Construção de Estratégias para a Bancarização da População de Baixa Renda com o Uso de Dispositivos Móveis. Tese de Doutorado, USP, 2009.

BRUSKY, B; FORTUNA, J. P. Entendendo a demanda para as microfinanças no Brasil: um estudo qualitativo de duas cidades. Rio de Janeiro: PDI/BNDES, 2002.

CASTILHOS, R. B.; ROSSI, C. A. V. Subindo o Morro: Consumo, Posição Social e Distinção entre Famílias de Classes Populares. Consumo na Base da Pirâmide: Estudos Brasileiros, cap.3, Rio de Janeiro, Mauad, 2009.

CHAUVEL, M. A.; SUAREZ, M. Consumidores Pobres e Insatisfação Pós-Compra: “Eles não têm Respeito pela Gente". Consumo na Base da Pirâmide: Estudos Brasileiros, cap.9, Rio de Janeiro, Mauad, 2009.

CASOTTI, L.; SUAREZ, M. F.N.; DELIZA, R. Consumo de Alimentos nas Famílias de Baixa Renda: Compartilhando Achados, Experiências e Aprendizados. Consumo na Base da Pirâmide: Estudos Brasileiros, cap.11, Rio de Janeiro, Mauad, 2009.

CHICK, G.; DONG, E. Possibility of Refining the Hierarchical Model of Leisure Constraints Through Cross-Cultural Research. Proceeding of the 2003, Northeastern Recreation Research Symposium.

CROWFORD, D. W., JACKSON E. L.; GODBAY, G. A Hierarquical Model of Leisure Constraints. Leisure Sciences, 13, 309-320.

DINIZ, F. e MOTTA, P. C. Em Busca de um Modelo de Restrição de Lazer para os Consumidores de Mais Idade. 30 encontro da ANPAD, Salvador, 2006.

GODBEY, G.; CRAWFORD, D. W. e SHEN, X. S. Assessing Hierarchical Leisure Constraints Theory After Two Decades. Journal of Leisure Research, Volume 42, no 1, pp 111-134, 2010.

HANDERSON, K. A. One Size Doesn't Fit All: The Meanings of Women's Leisure. Journal of Leisure Research, Volume 28, no 3, pp 139-154,1996.

HULTSMAN, W. Recognizing Patterns of Leisure Constraints: An Extension of 
Exploration of Dimensionality. Journal of Leisure Research, Volume 27, no 3, pp 228-244, 1995.

KYLE, G. T.; CHICK, G. The Social Nature of Leisure Involvement. Journal of Leisure Research, Volume 32, no 4, pp 426-448, 2002.

; MOWEN, A. J. An Examination of the Relationship Between Leisure Constraints, Involvement and Commitment. Proceedings of the 2003 Northeastern Recreation Research Symposium. Murdy, James, comp., pp 328-337, ed. 2004.

KLEIBER, D. et al. Having More by Doing Less: The Paradox of Leisure Constrais in Later Life. Journal of Leisure Research, vol. 40, no 3, 343-359, 2008.

JACKSON, E. L. Recognizing Patterns of Leisure Constraints: Results from Alternative Analyses. Journal of Leisure Research, Volume 25, no 2, pp 129-149, 1993.

Will Research on Leisure Constraints Still Be Relevant in the Twenty-First Century? Journal of Leisure Research, Volume 32, no 1, pp 62-68, 2000.

Leisure Constraints Research: Overview of a Developing Theme in Leisure Studies. Constraints to Leisure, Capítulo 1, Venture Publishing, 2005.

; DUNN, E. Is Constrained Leisure an Internally Homogeneous Concept? Leisure Science, Vol 13, no3, 167-184, 1991.

e SCOTT, D. Leisure Studies: Prospects for the Twenty-First Century. State College, Pa., Venture Publishing Inc., 1999.

MATTOSO, C. Q.; ROCHA, A. Significado do Crédito para Consumidores Pobres: Identidade, Distinção e Dádiva. Consumo na Base da Pirâmide: Estudos Brasileiros, Rio de Janeiro, cap.4, Mauad, 2009.

NADIROVA, A. e JACKSON, E. L. Alternative Criterion Variables Against Which to Assess the Impacts of Constrains to Leisure. Journal of Leisure Research, Volume 32, no 4, pp 396405, 2000.

NERI, Marcelo. A Nova Classe Média: 0 Lado Brilhante dos Pobres. FGV/CPS. Coordenação: Rio de Janeiro, 2008.

PONCHIO, M. C. e ARANHA, F. Necessidades, Vontades e Desejos: A Influência do Materialismo Sobre a Dívida de Consumo dos Paulistanos de Baixa Renda. Consumo na Base da Pirâmide: Estudos Brasileiros, cap. 7, Rio de Janeiro, Mauad, 2009.

ROCHA, A. da; SILVA, J. F. Consumo na Base da Pirâmide: Um Desafio para a Pesquisa. Consumo na Base da Pirâmide: Estudos Brasileiros, Rio de Janeiro, cap. 12, Mauad, 2009.

SHOGAN, D. Characterizing Constraints of Leisure: A Foucaultian Analisys of Leisure Constraints. Leisure Studies, 21, 27-38, Routledge, 2002.

SON, Julie S., KERSTTER, Deborah L. e MOWEN, Andrew J. Do Age and Gender Matter in the Constraint Negotiation of Physically Active Leisure? Journal of Leisure Research, Volume 40, no 2, pp 267-289, 2008.

VELOSO, Andrés Rodrigues, HILDEBRAND, Diogo F.N., ARTONI, Patricia R.C.D. e CAMPOMAR, Marcos C. A Criança no Varejo de Baixa Renda. Consumo na Base da Pirâmide: Estudos Brasileiros, Rio de Janeiro, cap.8, Mauad, 2009.

SUAREZ, Maribel, MOTTA, Paulo C., BARROS, Carla. Um Retrato das Relações de Consumo no Seriado A Diarista. Consumo na Base da Pirâmide: Estudos Brasileiros, cap.10, Rio de 
Janeiro, Mauad, 2009.

WHITE, Dave D. A Structural Model of Leisure Constraints Negotiation in Outdoor

Recreation. Leisure Studies, 30, 342-359, Routledge, 2008.

\section{Sites Pesquisados}

Veja. Baixa renda garante expansão do mercado de cartões. Disponível em http://veja.abril.com.br/noticia/economia/baixa-renda-garante-expansao-do-mercado-decartoes, consultado em 16/08/2011. 